\title{
Revision of the Genus Beatogordius (Gordiida, Nematomorpha). II. South American Species with Description of Two New Species
}

\author{
Cristina de Villalobos/ ${ }^{+}$, Andreas Schmidt-Rhaesa*, Fernanda Zanca
}

Facultad de Ciencias Naturales y Museo, Departamento de Invertebrados, Paseo del Bosque s/no 1900 , La Plata Argentina
*Zoomorphology and Systematics, University of Bielefeld, Bielefeld, Germany

Seven species of Beatogordius (Nematomorpha) have been reported from South America. A reinvestigation could not reproduce a number of determinations indicated in the literature. B. deshayesi has been a misinterpretation and the status of $\mathrm{B}$. irregularis appears to be very uncertain, because no generic characters could be found. The descriptions of $\mathrm{B}$. alfredi and $\mathrm{B}$. latastei confirm that these species belong to South America only. In B. abaiconus we found adhesive warts anterior of the male cloacal opening. These structures were to date only known from the genus Gordionus. In the posterior end of females from B. alfredi and B. variabilis, short paired rows of bristles were present which had to date only been known from the African species B. equinatus. Two new species, B. funis and B. palustre could be added to the genus.

Key words: Beatogordius - Nematomorpha - revision - scanning electron microscopy - South America

The genus Beatogordius Heinze, 1934 (Nematomorpha) was reported only for Africa and South America. The typical taxonomic character for this genus is the longitudinal striation of the cuticle caused by an arrangement of the areoles in lines parallel to the body axis. In the revision (Schmidt-Rhaesa \& de Villalobos 2002) by scanning electron microscopy (SEM) and light microscopy of the features of the 8 species cited in the literature from Africa, only 5 could be confirmed. The status of $B$. erythraeus (Camerano 1915) is very uncertain, because no generic characters could be found. The record for Africa (Sciacchitano 1958) of the South American species, B. alfredi (Camerano 1894) and B. latastei (Camerano 1895) is certainly wrong. Two new species $B$. brieni and $B$. ugandensis were added to the genus. The reinvestigation of the species, Chordodiolus echinatus, Linstow 1901 (Schmidt-Rhaesa \& de Villalobos 2002) demonstrated that due to the cuticular and to the posterior end of the females features (Schmidt-Rhaesa 2001a) this species should be included within the genus Beatogordius.

In the literature (Camerano 1894, 1895, Carvalho 1946, Miralles 1972, 1981, 1984, Villot 1874) 7 species of Beatogordius have been described in South America. In this paper we analyze by SEM the characteristics of South American species and compare them with the African species, thus completing the revision of all the described species belonging to the genus Beatogordius.

\section{MATERIALS AND METHODS}

In the literature 23 specimens of Beatogordius have been recorded from South America. We investigated 18

${ }^{+}$Corresponding author. Fax: $+54-221-4833871$. E-mail: villalo@museo.fcnym.unlp.edu.ar

Received 1 April 2002

Accepted 13 September 2002 of these specimens from the museums in Rio de Janeiro (Brazil), Paris (France) and La Plata (Argentina). Accession number, sex, original determination and collecting locality are listed in the Table. Sixteen further specimens were determined as $B$. variabilis, five as $B$. alfredi, one as $B$. lataste $i$ and two specimens corresponding to two new species from Museo de Ciencias Naturales La Plata (Argentina) were also included in the analysis (Table).

The exact sources of the material were as follows: (Persons who arranged loans are listed in parenthesis. Abbreviations are used throughout the text.) MNHNP: Muséum National d'Histoire Naturelle, Paris, France (JeanLou Justine); MNRJ: Museu Nacional, Rio de Janeiro, Brasil (Debora Pires); MLP: Museo de Ciencias Naturales, La Plata, Argentina (Cristina Damborenea).

Two males, one of $B$. alfredi and another of $B$. lataste $i$ were collected in summer (January 1999) in a small stream from the Cordoba province. One male specimen was collected in spring (November 2000) from Arias river in Salta and represents a new species. This material was fixed in $90 \%$ ethanol.

Longitudinal measurements of all the material analyzed were made with outstretched worms using a ruler. Diameters were measured under the dissecting microscope using a caliper ruler.

Cuticular sections were made as tangential sections to preserve the whole specimen or by cutting a piece of $0.5-1 \mathrm{~mm}$ if the specimen was already cut in two pieces.

To examine specimens by SEM, fragments of worms (anterior end, mid-body and posterior end) were washed in ultrasonic cleaners (Branson 1510), with distilled water and neutral detergent. Afterwards, they were rinsed twice with distilled water. They were dehydrated in a critical point dryer and gold-sputtered, observed and photographed (using JEOL SLM 1000).

All preparations (SEM stubs) are stored together with the ethanol preserved specimen in the respective museums. Measurements are given in micrometers. 
TABLE

Overview on the original and revised status of Beatogordius specimens investigated

\begin{tabular}{|c|c|c|c|c|c|}
\hline Original determination & Museo/Acc. No. & Sex & Type & Locality & Revised determination \\
\hline B. abaiconus & MNRJ 5 & $1 \mathrm{G}$ & $\mathrm{HL}$ & Brazil, Viçosa, MG & B. abaiconus \\
\hline B. alfredi & MLP 3642 & $2 \mathrm{E}$ & LT & Arg., Bs As, Tornquist & B. alfredi \\
\hline B. alfredi & MLP 3643 & $1 \mathrm{E}$ & LT & Arg., S. Ventana & B. latastei \\
\hline B. alfredi & MLP 3644 & $3 G$ & LT & Arg., Salta, Parque del Rey & B. alfredi \\
\hline B. alfredi & MLP 4922 & $1 G$ & LT & Arg., Cordoba & B. alfredi \\
\hline B. deshayesi & MHNAR 105 & $1 G$ & HL & Venezuela, Cumana & Paragordius tricuspidatus \\
\hline B. funis & MLP 4923 & $1 \mathrm{G}$ & HL & Arg., Salta, Oran & B. funis \\
\hline B. inesae & MLP 3147 & $1 \mathrm{G}$ & HL & Arg., Santiago del Estero & B. inesae \\
\hline B. latastei & MLP 3645 & $1 \mathrm{G}$ & LT & Arg., Cordoba, San Pelegrino & B. latastei \\
\hline B. latastei & MLP 4910 & $1 \mathrm{E}$ & $\mathrm{LT}$ & Arg., Córdoba, Villa Rosa & B. latastei \\
\hline B. palustre & MLP 4924 & $1 G$ & HL & Arg., Salta, Tres Palmeras & B. palustre \\
\hline B. variabilis & MLP 3646 a & $1 G$ & HL & Arg., S. Ventana, El Pinar & B. variabilis \\
\hline B. variabilis & MLP 3646 b & $2 G-3 E$ & PT & Arg., S. Ventana, El Pinar & B. variabilis \\
\hline B. variabilis & MLP 3647 & $12 G-3 E$ & PT & Arg., S. Ventana, El Pinar & B. variabilis \\
\hline B. variabilis & MLP 3648 & $3 G$ & PT & Arg., S. Ventana, El Pinar & B. variabilis \\
\hline B. variabilis & MLP 3660 & $4 \mathrm{E}$ & PT & Arg., S. Ventana, El Pinar & B. variabilis \\
\hline
\end{tabular}

MNRJ: Museu Nacional, Rio de Janeiro, Brasil; MLP: Museo de Ciencias Naturales, La Plata, Argentina; MNHNP: Muséum Nationales d'Histoire Naturelle, Paris, France; HL: holotype; PT: paratype; LT: lectotype; Arg: Argentina; Bs As: Buenos Aires; MG: Minas Gerais; S: Sierra

Taxonomic characters - For better orientation we first introduce the characters of taxonomic importance of Beatogordius species. They refer to the cuticular structure at midbody and the posterior end of males and females.

The body cuticle bears more or less elevated structures called areoles and interareolar structures: spines, bristles or tubercles. The areoles are arranged pairwise in lines parallel to the body axis (e.g. Figs 4C, 6D). The stripes caused by the areoles are not always continuous (e.g. Fig. 6C). The pairs of areoles are in some cases so close together that they seem to fuse (e.g. Fig. 1C) or the areoles of a same pair are separated by a furrow which can be narrow (e.g. Fig. 5) or broad (e.g. Fig. 8C). Separating the pairs of areoles we find an interareolar furrow with or without interareolar structures.

The anterior tip is usually white or whitish, followed by a dark ring, posterior of which the "normal" coloration of the body starts. These characters are called white cap or calotte and dark collar or pigment ring.

The posterior end of the male is clearly bilobed. The cloacal opening is ventral and subterminal. The cloacal opening can be surrounded by bristles called circumcloacal bristles. Anterolateral to the cloacal opening are paired rows of bristles arranged in parabolic rows, these bristles can be unbranched or furcated. Posterior to the cloacal opening and usually extending onto the inner side of the tail lobes are short spinelike cuticular structures called spines.

The female posterior end is round. The cloacal opening is terminal with no circumcloacal bristles. On the ventral side (Fig. 3A) or on the dorsal side as well as on the ventral side (Figs 9A, B) there are paired rows of bristles, arranged in a "V"-like pattern and directed towards the cloacal opening.

\section{RESULTS}

Beatogordius abaiconus Carvalho, 1946

Fig. 1

1946 Beatogordius abaiconus Carvalho. Boll. Mus. Nac. $62: 1-8$

Holotype: 1 G(MNRJ 5): BRAZIL Viscosa, Minas Gerais. Col. Carvalho 4-4-45

Material examined: holotype: SEM of anterior end, posterior end and midbody

Host: unknown

Description: body light brown. Ventral midline slightly darker. Dark collar slightly evident. Anterior end tapering (Fig. 1A). Mouth subterminal. Posterior end is bilobed (Fig. 1B). Length of lobes 234.7, width 104.3. The cloacal opening is round, diameter 38.9. Anterolateral of the cloacal opening is a parabolic row of bristles, most of which are apically multifurcated. Posterior of the cloacal opening and extending onto the inner side of the tail lobes are short conical spines.

The cuticle contains areoles (they appear to be clustered in pairs adjoining one long side) (Fig. 1C) that are rectangular or polygonal with lengths which vary from 27.3 to 8.7 and widths from 6.2 to 12.5 . Between the areoles of the same pair there is a very narrow furrow (0.8) which is sometimes difficult to delimit. The interareolar furrow is narrow (0.9) but well delimited. In this interareolar furrow there are only a few blunt tubercles not higher than the areoles. In the anteroventral cuticle of the cloacal opening, isolated elongated structures were found arranged in two rows, parallel to the longitudinal axis of the body. Length of these elongated structures 7.7 (Fig. 1D) located between or on the areoles. The cuticle of the anterior region has the same features as that of the midbody. 
Dimensions: (length and diameter in mm) MNRJ 5: 35/0.3. Comments: our observations of the cuticle features under SEM differ from the original description, (Carvalho 1946) no transversal furrows dividing areoles were found. However, elongated structures anteroventral of the cloacal opening were observed. These structures were described by Müller (1927) for Gordionus as adhesive warts. By SEM, structures in a comparable location were reported by Cham et al. (1983) and de Villalobos et al. (2001) for $G$. wolterstorffii and were also found in specimens assigned
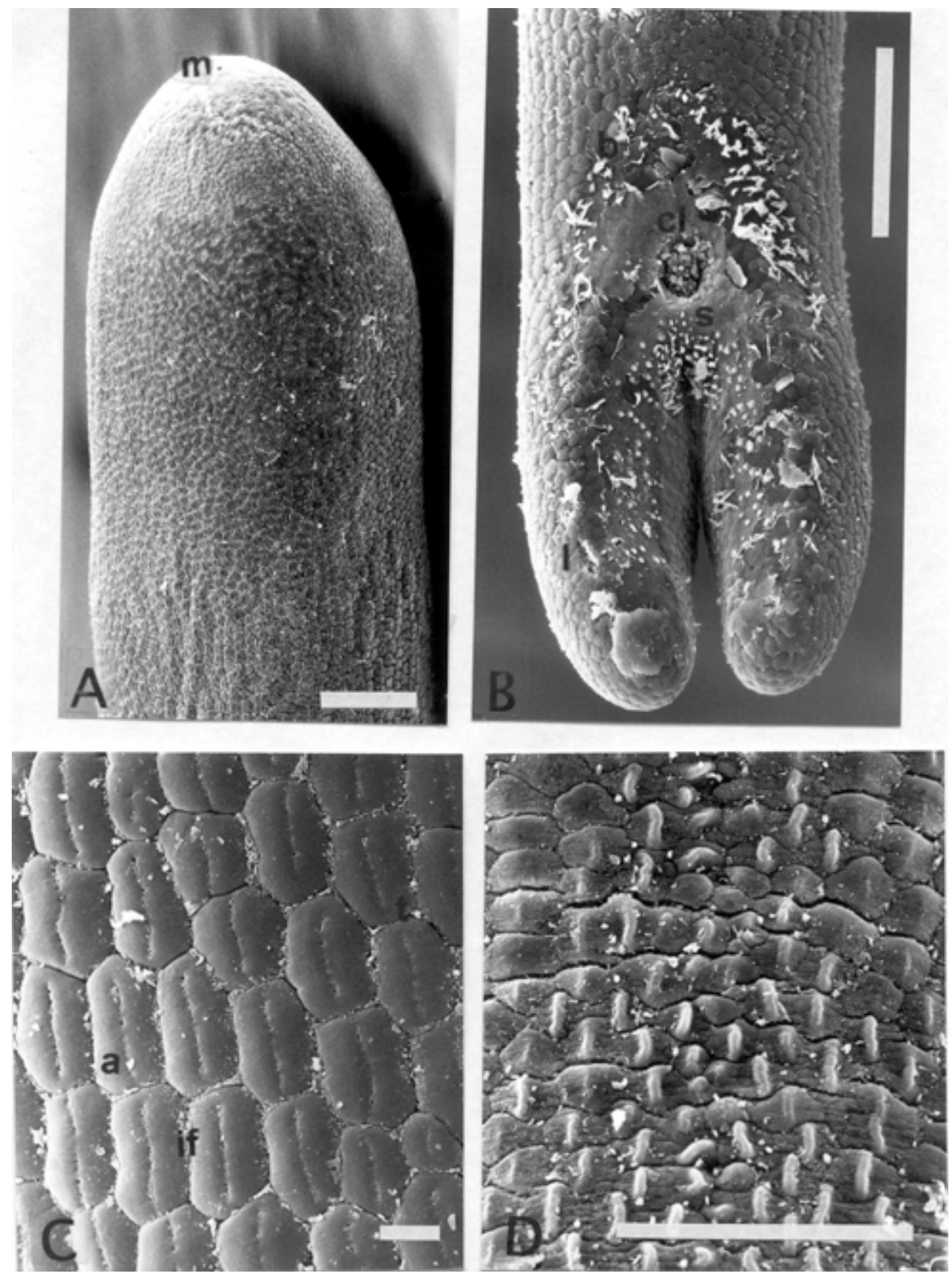

Fig. 1: scanning electron photographs of male of Beatogordius abaiconus, holotype. A: anterior end, scale bar $=100 \mu \mathrm{m}$; B: ventral view of posterior end showing tail lobes, rows of bristles and spines posterior of the cloacal opening, scale bar $=100 \mu \mathrm{m}$; C: cuticle showing longitudinal stripes of fused areoles, scale bar $=10 \mu \mathrm{m}$; D: ventral view of elongate structures anteroventral of the cloacal opening, scale bar $=10 \mu \mathrm{m} ; \mathrm{a}$ : areole, cl: cloacal opening, 1: lobe, m: mouth, s: post-cloacal spines 
to G. violaceus (Schmidt-Rhaesa 2001b). Finding adhesive warts in B. abaiconus modifies the concept of using these structures as a diagnostic feature of Gordionus.

\section{Beatogordius alfredi (Camerano 1894)}

Figs 2, 3

1894 Gordius alfredi Camerano, Boll. Zool. Anat. Comp. Torino 9 (175)

1897 Parachordodes alfredi Camerano, Mem. R. Accad. Sci. Torino p. 52
1934 Beatogordius alfredi Heinze, Zool. Anz. 106: 192

Holotype: 1 G ARGENTINA Tucumán, San Pablo

Additional specimens: ARGENTINA: $2 \mathrm{G} 2 \mathrm{E}$ Salta, Tala (No accession number); 3G (MLP 3644) Salta, Parque Nacional Del Rey. Buenos Aires, 2E (MLP 3642) Balneario Tornquist; 1E (MLP 3643) Sierra de La Ventana, Estación de Piscicultura; 1G (MLP 4922) Córdoba Alto Lindo. BRASIL: 1G Viçosa Minas Gerais (no accession number). Remarks: holotype and 2 G 2E specimens from Argentina Salta, Tala are not in the collection of the Museo
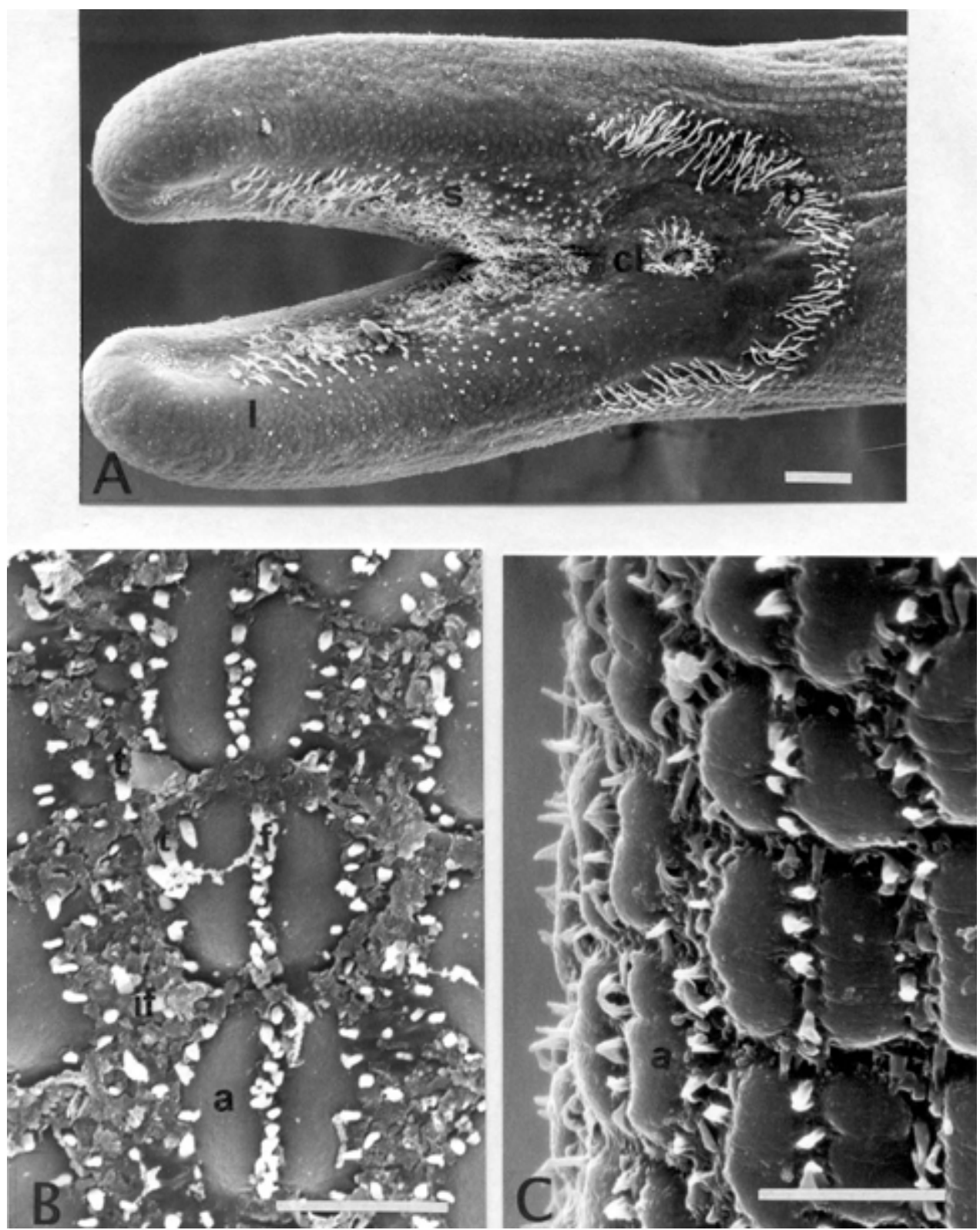

Fig. 2: scanning electron photographs of male of Beatogordius alfredi. A: ventral view of posterior end showing tail lobes, rows of bristles and spines posterior of the cloacal opening (MLP 3644), scale bar $=100 \mu \mathrm{m}$; B: cuticular structure in midbody (MLP 3644), scale bar $=10$ $\mu \mathrm{m}$; C: cuticular structure in midbody (MLP 4922), scale bar $=10 \mu \mathrm{m}$; a: areole, b: bristles, cl: cloacal opening, f: furrow, if: interareolar furrow, 1: lobe, s: post-cloacal spines, t: tubercle 
Regionali di Science Naturali, Torino, Italy as indicated by Camerano (1897a). The specimen from Brazil Viçosa Minas Gerais is not in the collection of Museu Nacional Rio de Janeiro, Brazil, unfortunately it seems to be lost. Material examined: SEM of anterior end, posterior end and midbody. 3G (MLP 3644); 2E (MLP 3642); 1G (MLP 4922); 1E (MLP 3643)

Host: unknown

Description: the anterior end is slightly conical in shape. A white cap and dark collar are present at the anterior tip of specimens. The body is light brown. The posterior end of the males has tail lobes with a length from 346 to 527.2. and a width from 149 to 236 (Fig. 2A). The cloacal opening is oval and ventral and surrounded by circumcloacal bristles. There is a parabolic row of bristles anterior and lateral of the cloacal opening. Maximum length of bristles 36 and may be simple, bi-or trifurcated. Posterior of the cloacal opening and extending onto the inner side of the tail lobes are short conical spines that become elongated and bristle-like towards the posterior end of the tail lobes reaching lengths of 8-15 (details of the posterior end according to Carvalho1944).

The cuticle of specimens from Buenos Aires and Salta (Fig. 2B) contains oval areoles with a smooth surface. The areoles are arranged in pairs, forming lines parallel to the body. The areoles of a same pair are separated by a narrow furrow (1.4) which has round apex tubercles most of them arranged in paired lines. The interareolar furrow is
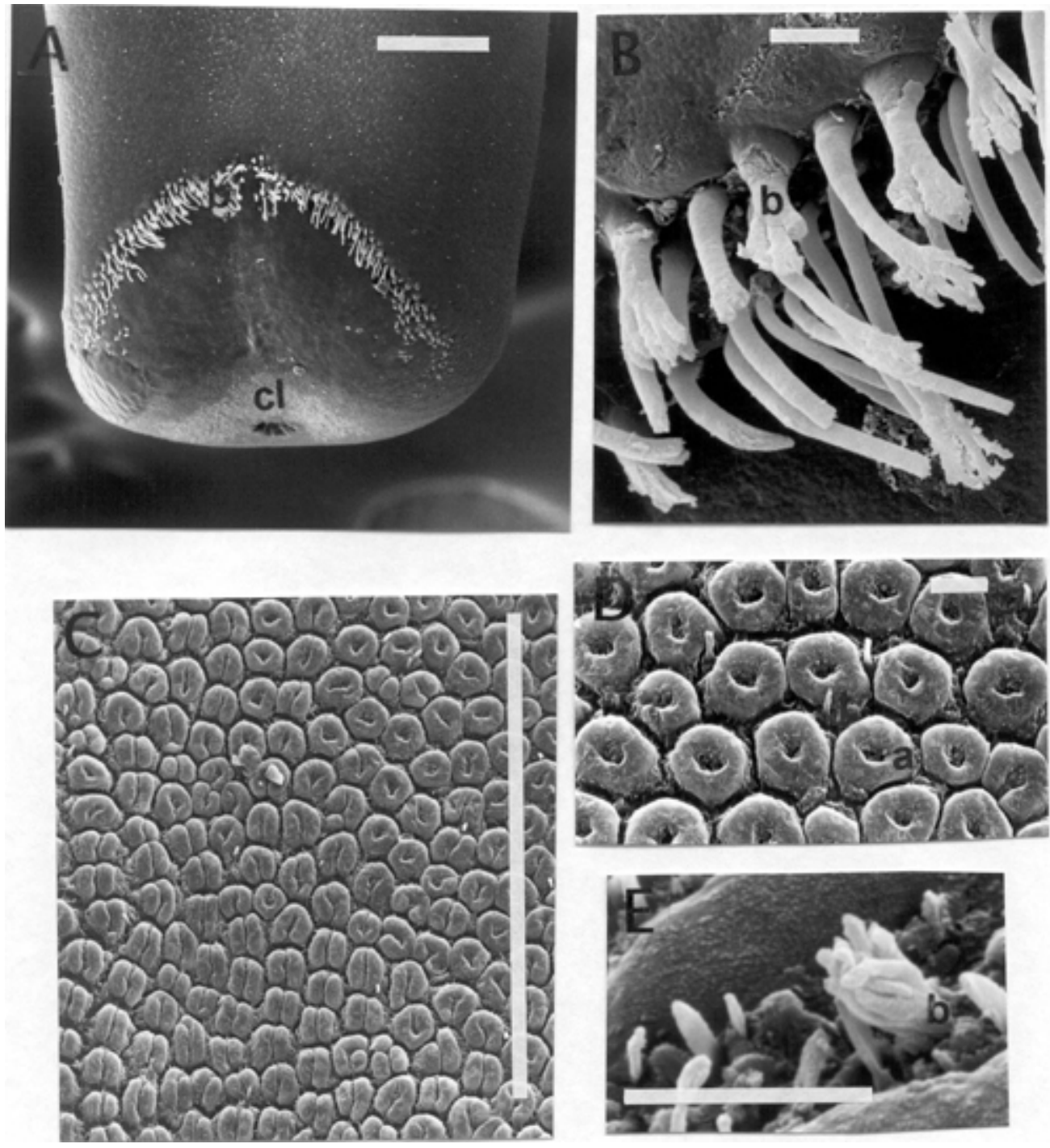

Fig. 3: scanning electron photographs of Beatogordius alfredi. A: ventral view of female posterior end showing rows of bristles and cloacal opening (MLP 3642), scale bar $=100 \mu \mathrm{m}$; B: terminally multifurcated bristles of the rows of female posterior end (MLP 3642), scale bar $=10 \mu \mathrm{m} ; \mathrm{C}$ : areolar pattern in the anterior end with transitional and modified patterns compared to midbody (MLP 3644), scale bar $=100$ $\mu \mathrm{m}$; D: cuticular details of anterior end showing areoles like "donuts" (MLP 3644), scale bar = $10 \mu \mathrm{m}$; E: interareolar treelike tubercles (MLP 4922), scale bar $=0.4 \mathrm{~mm}$; a: areole, b: bristles, cl: cloacal opening 
wide (7.8), with sharp ended tubercles, more abundant next to the areolar borders. The stripes caused by the arrangement of the areoles are not always continuous. In the specimen from Córdoba (Fig. 2C) the areoles are rectangular and between the pair of areoles there is only one row of bristles and the interareolar furrow is narrower (1.9) and with less tubercles than the specimens from Salta and Buenos Aires.

Female: the posterior end is round but with a well defined furrow in the ventral side with paired rows of bristles, arranged in a "V" like pattern (Fig. 3A). These bristles have a maximum length of 38.3 and their ends are ramified (Fig. 3B). The cloacal opening is irregular in shape and without circumcloacal bristles.

In all the material examined, the cuticle next to the anterior end undergoes a transformation (Fig. 3C) where the areolar pairs lose their typical longitudinal arrangement observed in the midbody. They get shorter and seem to fuse first forming a horseshoe shape and then close forming a circular areole which surrounds a central cavity (like donuts). Some of the circular areoles have a tubercle between them (Fig. 3D). In the interareolar furrow of a male specimen from Buenos Aires (MLP 4922) a group of tubercles fused at the bottom and with the ends free (like trees) (Fig. 3E) was found.

Dimensions: (length and diameter in mm) MLP 3643: $1 \mathrm{E}$ 129/0.5. MLP 3644: 3G133/0.4, 164/0.5, 148/0.5 and 2E 145/ 0.6, 155/0.7. MLP 3642: 200/0.7, 222/0.6. MLP 4922: 168/0.6 Comments: the specimens analyzed share the cuticular features described by Camerano (1894, 1897a, 1897b) for B. alfredi, but Camerano does not analyze the fine features of the female posterior end in any of these works.

The features of the female posterior end under SEM of $B$. alfredi, are coincident with the observations realized for B. echinatus (Linstow 1901) female by Schmidt- Rhaesa 2001a). It is important to note that the cuticle in all the specimens examined showed variations in both the shape and the areolar arrangement in the anterior end of the body. One female (MLP 3643) determined by Miralles (1988) as B. alfredi was transferred due to cuticular features to B. latastei.

\section{Beatogordius deshayesi (Villot 1874)}

1874 Gordius deshayesi Villot. Arch. Zool. Exp. Gen. 3: 43-72

1952 Beatogordius deshayesi Heinze. Z. Parasitenkd. 15: 183- 202

Holotype: 1G(MHNA2 R 105.1866) VENEZUELA Cumaná Material examined: holotype: SEM of posterior end and midbody

Host: unknown

Description: Villot (1874) describes a specimen, without specifying sex, remarking that the epidermis had noticeable thick palps arranged in longitudinal rows. Divergent lines from each palp connected with the other palps forming an approximately regular rhomboidal pattern. Camerano (1890) although coincident with Villot in taxonomic position disagrees with his interpretation and designation of cuticle. Dorier (1946) redescribes this specimen identifying it as a female and poses doubts about the taxonomic position of this species. Heinze (1952) considering Dorier's questions transfers this species to the genus Beatogordius. In our analysis of the holotype we observe that the posterior end corresponded to a male with two very close lobes (this probably led Dorier to confuse this specimen with a female). Anterior of the cloacal opening there is no parabolic or $\mathrm{V}$-shaped row of bristles. Under SEM the cuticle presents characteristics similar to Paragordius tricuspidatus (de Villalobos et al 2001) but very different from the features of Beatogordius. We therefore consider that the male specimen described as $B$. deshayesi is a misinterpretation.

\section{Beatogordius funis n.sp.}

Fig. 4

Holotype: 1G (MLP 4923) ARGENTINA, Salta, Oran Material examined: holotype: SEM of midbody

Host: emerged from Blatta orientalis

Description: the body is dark brown, a dark collar behind the white cap is clearly visible. Anterior end is tapering. The posterior end is bilobed (Fig. 4A); the lobes have a length of $371.4 \mathrm{~mm}$ and a diameter of $142.8 \mathrm{~mm}$. The ventral cloacal opening is surrounded by circumcloacal bristles with posterior short conical spines which extend onto the inner and the ventral side of the tail lobes. Towards the terminal end of the lobes, the spines become elongated. Anterior of the cloacal opening is a paired anterolateral rows of bristles. Bristles are multifurcated (Fig. 4B).

The cuticle along the body contains quadrangular areoles (Fig. 4C) arranged in pairs, with a length varying from 8.2 to $11.3 \mathrm{~mm}$. and a width from 7.4 to $10.1 \mathrm{~mm}$. Between the areoles of the same pair round apex tubercles are observed which continue with the inferior and superior areoles from the same line forming a continuous longitudinal stripe (Fig. 4D). The interareolar furrow is covered by interwoven cuticular projections originating in the lateral area of the areoles with a few tubercles emerging among them. The cuticle of the anterior region shares the same features with the cuticle of the midbody.

Dimensions: length $155 \mathrm{~mm}$, diameter $0.4 \mathrm{~mm}$

Comments: this species differs from other known Beatogordius-species in the cuticular pattern. As in $B$. abaiconus and $B$. palustre n.sp. there is no variation in the cuticle of the anterior region.

\section{Beatogordius inesae (Cavalieri, 1961)}

Fig. 5

1961 Gordius inesae Cavalieri, Neotropica 7 (22): 3

1984 Beatogordius inesae Miralles. Neotropica 30 (83): 125-126

Holotype: 1G (MLP 3147) ARGENTINA, Santiago del Estero

Material examined: holotype: SEM of midbody

Host: specimen obtained from the vomit of an adult man Description: unfortunately, the anterior and posterior ends seem to have been lost so that its description is based on the drawings made by Cavalieri (1961). Anterior end tapering, white cap and dark collar are clearly visible. The posterior end with two robust lobes $0.3 \mathrm{~mm}$ long; the cloacal opening surrounded by a slightly noticeable dark 
ring. The author says nothing about the absence or presence of spiniform structures or rows of bristles anterior to the cloacal opening.

The cuticle of the midbody studied under SEM is formed by pairs of areoles arranged in lines parallel to the body axis (Fig. 5A). The areoles are rectangular with a length varying from 6.4 to $12 \mathrm{~mm}$ and a diameter from 6 to $8.4 \mathrm{~mm}$. The areoles belonging to the same pair seem to be united by small cuticular bridges. The interareolar furrow is very narrow (2) being traversed by projections arising from the lateral face of the areoles and ending in a round shape. A wide and slightly pointed tubercle is rarely found in the interareolar furrow. Unfortunately, as the body ends are missing we were not able to analyze the existence of a cuticular variation in them.

Dimensions: length $168 \mathrm{~mm}$, diameter $0.5 \mathrm{~mm}$ (Cavalieri 1961).

Comments: B. inesae features resemble B. abaiconus, but differ in the limits separating the areoles of each pair which are well defined, being the interareolar furrow wider. Although it seems unlikely that humans may serve as regular hosts, there are several reports in the literature (Carvalho 1942, Faust \& Botero Ramos 1960, Cappucci 1982, Schmidt-Rhaesa 1997) of the occurrence of
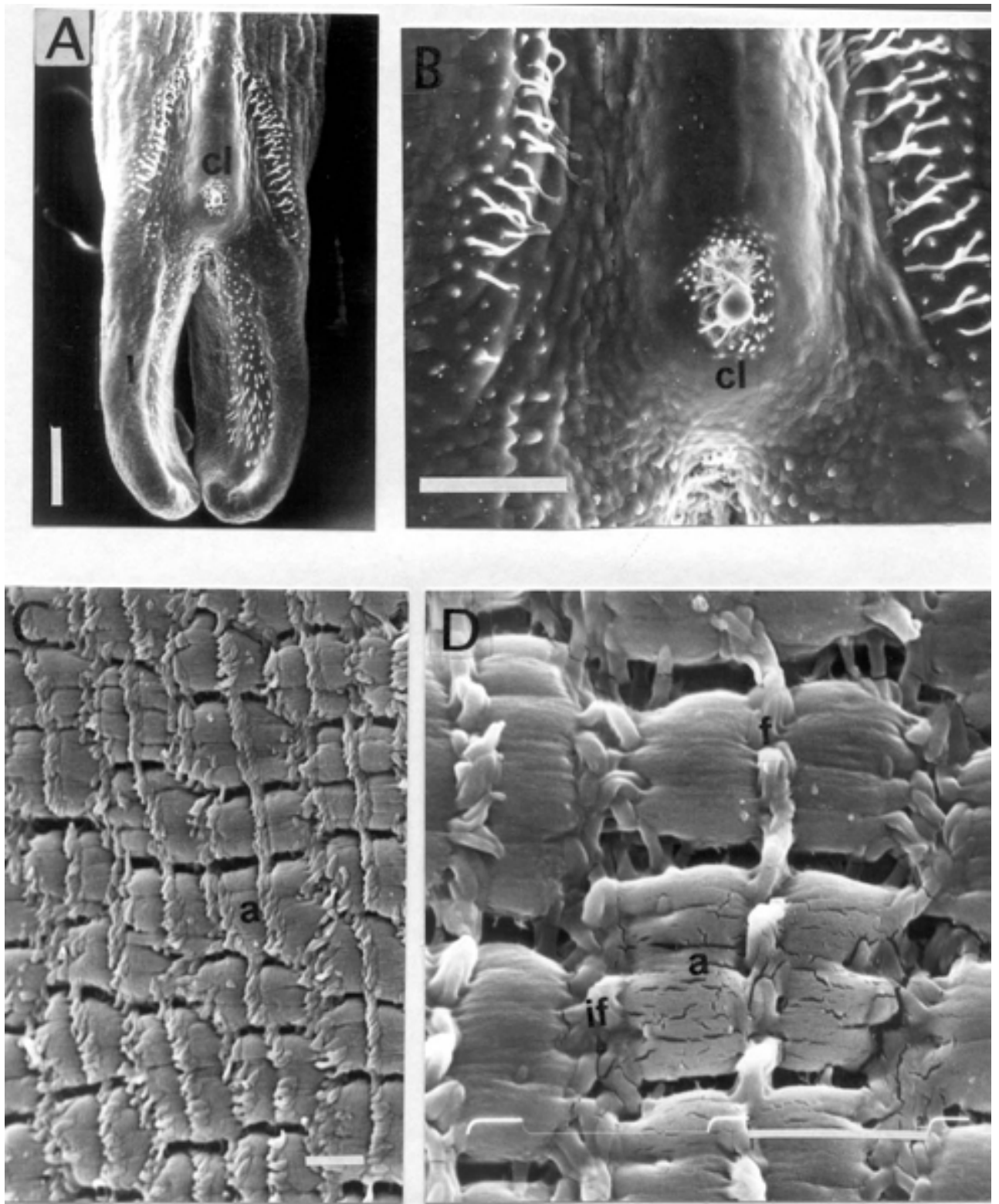

Fig. 4: scanning electron photographs of male of Beatogordius funis n. sp. holotype. A, B: ventral view of posterior end showing tail lobes, rows of bristles, circumcloacal spines and spines posterior of the cloacal opening, scale bars = A: $100 \mu \mathrm{m}, \mathrm{B}: 0.25 \mathrm{~mm}$; C, D: cuticle showing longitudinal stripes of fused areoles, scale bar $=10 \mu \mathrm{m}$; a: areole, cl: cloacal opening, f: furrow, if: interareolar furrow, l: lobe 
Nematomorpha in humans. For this reason it is interesting to notice that this specimen was obtained alive from the vomit of an adult man, probably ingested with the contaminated water from a stream or a river.

\section{Beatogordius irregularis Miralles 1972}

1972 Beatogordius irregularis Miralles. Neotropica 18: 122-125

Holotype: 1 E ARGENTINA, Mendoza, Chacras de Coria Material examined: none [holotype is not in the collection of the Museo de Ciencias Naturales de La Plata as indicated by Miralles (1972)]

Host: unknown

Description: according to Miralles (1972) the areoles are irregularly arranged without forming the characteristic longitudinal stripes caused by an arrangement of the areoles in lines parallel to the body axis. In the interareolar spaces there are short structures, described by Miralles (1972) as refringent points scattered or grouped, star-like in shape with four radii starting at the centre.

Dimensions: length $283 \mathrm{~mm}$, diameter $1.09 \mathrm{~mm}$

Comments: according to the original description (Miralles 1972) the cuticular features of this species differ from the general pattern observed in other Beatogordius species. The areoles are irregularly distributed and never form longitudinal parallel series. The features of the terminal end of the female are not detailed. A reinvestigation of this species to clarify fine structural details would be valuable.

\section{Beatogordius latastei (Camerano, 1895)}

Fig. 6

1895 Gordius latastei Camerano. Actes Soc. Sci. Du Chili 5:8

1897 Parachordodes latastei Camerano. Mem. Acad. R. Delle Sci. Torino: 52

1934 Beatogordius latastei Heinze. Zool. Anz. 106: 192
1972 Beatogordius latastei Miralles. Neotropica 18: 122124

Holotype: 1G CHILE, Santiago de Chile in potable water Additional specimens: ARGENTINA: 1 G (MLP 3645) Córdoba, San Pelegrino ; 1 G (MLP 4910) Córdoba, Villa Rosa; 1E (MLP 3643) Buenos Aires, Sierra de La Ventana, Arroyo del Negro.

[ Holotype is not in the collection of the Museo Regionali di Science Naturali, Torino, Italy as indicated by Camerano (1897b)]

Material examined: MLP 3645: SEM posterior end. MLP 4910: SEM of anterior end, midbody and posterior end Host: unknown

Description: all specimens are light to medium brown. The anterior end is tapering, white cap and dark collar are present. The posterior end of the male is bilobed (Fig. 6A) the lobes are 367 long with a diameter 89.2. The cloacal opening is ventral, oval and surrounded by short spines. There are rows of bristles anterolateral of the cloacal opening (Figs $6 \mathrm{~A}, \mathrm{~B})$. Posterior of the cloacal opening are conical spines. The cuticle surrounding the cloacal opening is smooth.

The cuticle in the midbody (Fig. 6C), contains long and thin parallel longitudinal stripes formed by pairs of areoles. The areoles, of smooth surface are oval with a length averaging 11.2 and a width averaging 3.5 The areoles of a same pair are separated by a narrow furrow (1.4) with only a few small tubercles. These areolar stripes (Figs $6 \mathrm{C}, \mathrm{D})$ are separated from each other by a wide interareolar furrow (7.9) which is structured by cuticular folds (Fig. $6 \mathrm{D})$. The tubercles in this furrow are abundant in the lateral face of the areoles and scarce in the medial area. These tubercles, with rounded or pointed ends, vary in length from 1.3 to 4.4 . The transversal furrows separating the pairs of areoles are narrow (2.2) and sometimes difficult to delimit because of the connection of the anterior and pos-

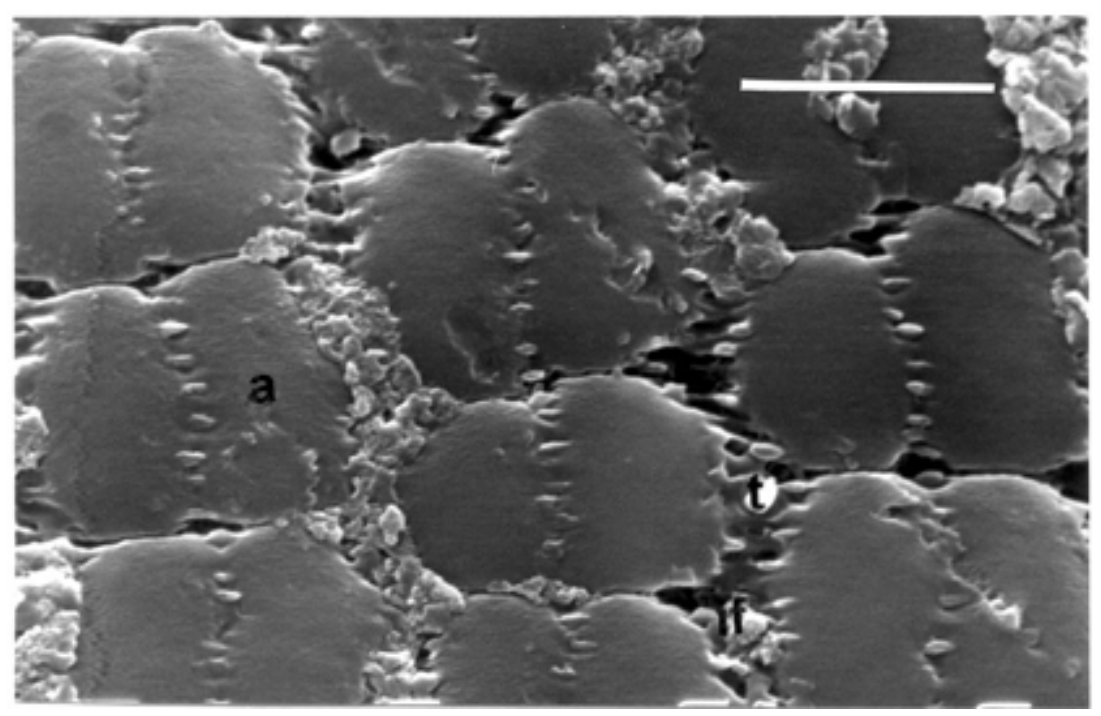

Fig. 5: scanning electron photographs of male of Beatogordius inesae, holotype. Cuticle showing longitudinal stripes of fused areoles, scale bar $=10 \mu \mathrm{m}$; a: areoles, if: interareolar furrow, t: tubercle 
terior ends in some pairs of areoles. It is unusual to observe tubercles in these furrows. In the cuticle of the anterior region (Fig. 6E) the areoles are rectangular or quadrangular with no tubercles separating each other, the longitudinal furrow separating the pairs of areoles is narrower (5.3) and there are small tubercles very scattered. The terminal end of the female has the same features as observed in B. alfredi.
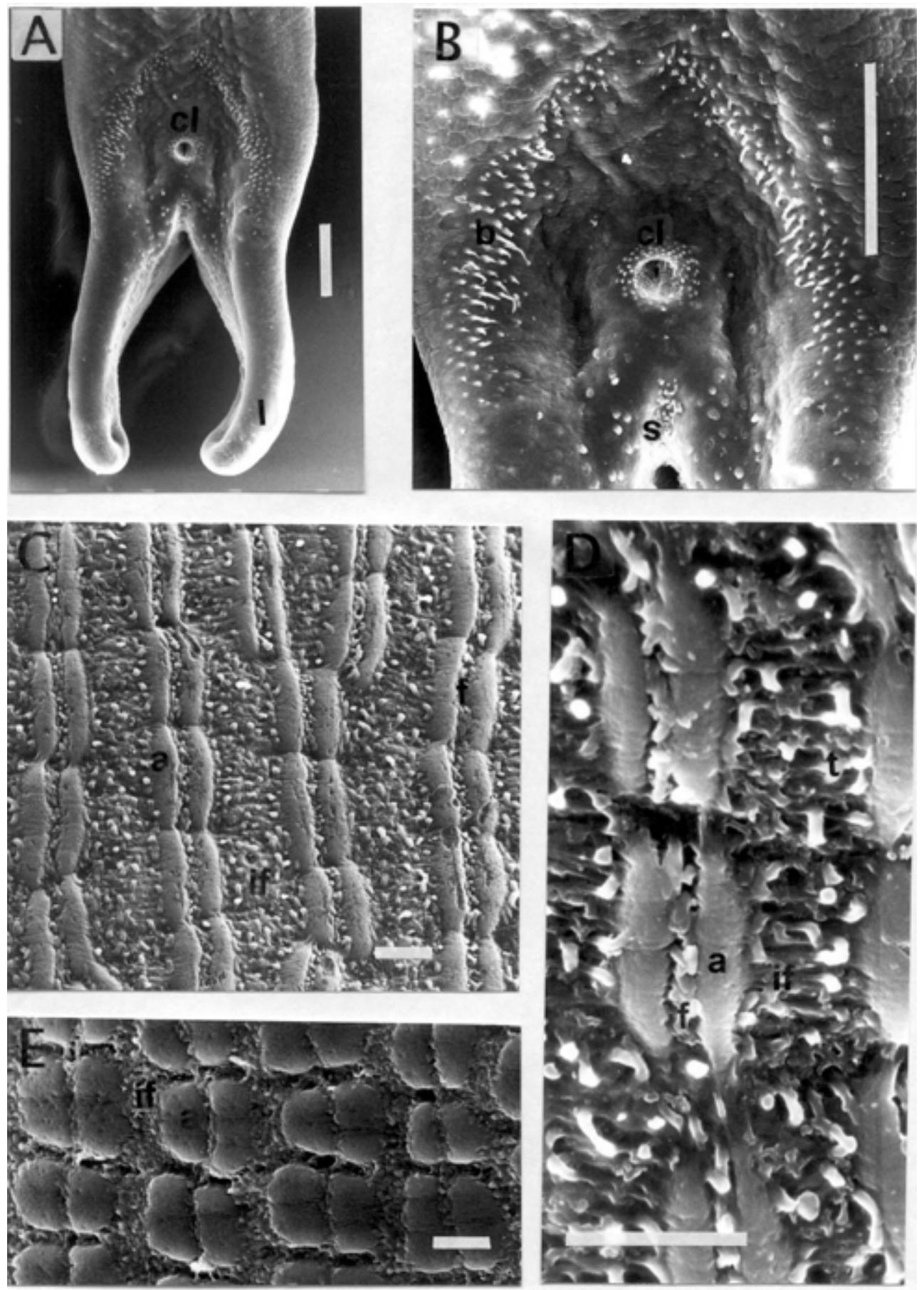

Fig. 6: scanning electron photographs of male of Beatogordius latastei. A, B: ventral view of posterior end showing tail lobes, rows of bristles, circumcloacal spines and spines posterior of the cloacal opening (MLP 3645), scale bars $=100 \mu \mathrm{m}$; C, D: cuticle showing longitudinal stripes of fused areoles, scale bars. C: $10 \mu \mathrm{m}, \mathrm{D}: 0.3 \mathrm{~mm}$, E: cuticle of the anterior end with modification of the pattern as show in midbody (MLP 4910), scale bar $=10 \mu \mathrm{m}$; a: areoles, b: bristles, cl: cloacal opening, f: furrow, if: interareolar furrow, 1: lobe, s: post-cloacal spines, t: tubercle 
Dimensions: measurements were as follow: (length in $\mathrm{mm} /$ diameter in mm) holotype: 140/0.5; MLP 3645: 150/0.62; MLP 4910: 164/ 0.8; MLP 3643: 128/0.4

Comments: two female specimens (AMT 25697 and AMT 29018) from Congo Belga were determined by Sciacchitano (1958) as B. latastei but as their areoles are arranged in the shape of an " $\mathrm{H}$ ", horizontal elements not observed in B. latastei, and as the posterior end resembles the one of $B$. echinatus, these two female specimens were assigned to B. echinatus (Schmidt-Rhaesa \& de Villalobos 2002). B. latastei has only been reported in South America (Camerano 1895, Miralles 1972). Camerano (1895) in the original description distinguishes this species of $B$. alfredi, by its areolar shape, the wide space of the interareolar furrow and the absence of tubercles in the furrow separating the pair of areoles. Our reinvestigation concerning the body cuticle by SEM, coincides with the observations made by Camerano $(1895,1897 \mathrm{~b})$. The shape of the posterior end of the male of $B$. latastei is unique in that the lobes appear thin and wiry. This is in contrast to all other males presented in this study, which have thick almost robust posterior lobes. Future studies on other male specimens of $B$. lataste $i$ will allow to determine if this is a specific character.

\section{Beatogordius palustre $\mathrm{n}$. $\mathrm{sp}$. Fig. 7}

Holotype: 1G (MLP 4924) ARGENTINA, Salta, Tres Palmeras, Río Arias

Material examined: Holotype: SEM of anterior end, posterior end and midbody

Host: unknown

Description: the body is dark brown, a dark collar behind the white cap is clearly visible. Anterior end is tapering. The posterior end is bilobed (Fig. 7A) the lobes are 387 $\mathrm{mm}$ long with a diameter of $125 \mathrm{~mm}$. Unfortunately the cloacal opening was partly covered with dirt. Anterolateral of it are rows of bristles.

The cuticle of the whole body contains rectangular areoles, arranged in longitudinal rows (Fig. 7B). They vary from 18.7 to $31.2 \mathrm{~mm}$ in length and from 7.5 to $13.7 \mathrm{~mm}$ in width. The areolar borders are very irregular and some areoles of a same pair are linked to each other in one of the ends. The interareolar furrows and the furrows separating the areoles of a same pair are very narrow (2). Interareolar structures are very scattered and rare, represented by blunt ended tubercles $3.8 \mathrm{~mm}$ long (Fig. 7C).

Dimensions: (length and diameter in mm) MLP 4924: 189/0.3. Comments: the cuticle of Beatogordius palustre shows some resemblance to B. abbreviatus from Africa, in the similar shape of the areoles and also because they often appear to be clustered in pairs adjoining with one long side. But they differ because B. abbreviatus has the tubercle areoles with a round base and a tubercle on top (Schmidt-Rhaesa and de Villalobos, in press) which is not present in B. palustre.

\section{Beatogordius variabilis Miralles, 1981}

$$
\text { Figs } 8,9
$$

1981 Beatogordius variabilis Miralles. Neotropica 27 (77): 87-90
Holotype: 1G (MLP 3646a) ARGENTINA, Sierra de La Ventana, El Pinar, El Loro river

Additional specimens: ARGENTINA: $2 \mathrm{G} 3 \mathrm{E}$ (MLP 3646b), 12 G 3E (MLP 3647), 3G (MLP 3648), 4E (MLP 3660) Sierra de La Ventana, El Pinar, El Loro river. 1E (MLP 4910) Córdoba, Alto Lindo

Material examined: SEM of anterior end, midbody and posterior end: MLP 3646a, MLP 3646b, 5G 2E MLP 3647, MLP 3648, 2E MLP 3660, MLP 4910

Host: unknown

Description: male. A calotte and dark collar are present at the anterior tip of specimens. Mouth opening subterminal. Cylindrical body with a diameter of $0.5 \mu \mathrm{m}$ approximately constant in its whole length. The body is usually light brown. Dorsal and ventral longitudinal furrows slightly evident. The posterior end is bilobed (Fig. 8A) the lobes with an average length of $408.6 \mathrm{~mm}$ and an average width of $187.8 \mathrm{~mm}$. The ventral cloacal opening is round and is surrounded by undivided circumcloacal spines (Fig. 8B) (12.9). Anterior to the cloacal opening there is a parabolic or $\mathrm{V}$-shaped row of bristles extending onto the level of bifurcation. Bristles are always furcated and most of them are terminally divided into several short branches (Fig. 8B). Posterior to the cloacal opening are short conical spines which extend onto the inner and the ventral side of the tail lobes. The cuticle surrounding the cloacal opening and the internal face of the lobes is completely smooth.

The midbody cuticle (Fig. 8C) contains pairs of irregular and rectangular areoles with a length averaging 9.68 $\mathrm{mm}$ and a width averaging $6.32 \mathrm{~mm}$. The areolar surface is completely rugged. Between the areoles of a same pair there is a narrow furrow (0.9) from which short round ended tubercles not higher than the areoles emerge (1.2). These tubercles are arranged in double rows. The interareolar furrow is wider (2.9), traversed by cuticular projections coming from the lateral borders and contacting the pairs of areoles to each other. Blunt apex tubercles arranged very close to the lateral borders of the areoles are observed in this furrow, as well as some pores. The cuticle shows a transition from the midbody towards the anterior end, where initially, the areoles in each pair although arranged in a line (Fig. 8D) are more separated from each other and from the rest of the other pairs of areoles. Then the areoles in each pair fuse by their anterior ends forming a V-like shape or their fusion is almost complete forming a donut-like shape (Fig. 8E).

Female: posterior end (Figs 9A, B) complete and round with smooth terminal cloaca without circumcloacal bristles. Showing a difference from the females of $B$. alfred $i$ and $B$. latastei, in the posterior end of B. variabilis, rows of bristles in the dorsal and ventral surface are observed. In the ventral face (Fig. 9B) the bristles are longer and more abundant than in the dorsal face (Fig. 9A). The cuticle has the same features observed in males in the medial region as well as in the anterior end.

Dimensions: measurements were as follows: (length in $\mathrm{mm} /$ diameter in $\mathrm{mm}$ ) holotype MLP 3646: 230/0.59 mm according to Miralles (1981), own measurements: $232 / 0.57$ Paratype males: length from 90 to $199 \mathrm{~mm}$ diameter from 0.3 to $0.5 \mathrm{~mm}$. Females: 152 to $163 \mathrm{~mm}$ in length and $0.5-0.8$ mm diameter. 
Comments: Miralles (1981) describes for the first time in a species of Beatogordius the cuticular variation in the shape and areolar arrangement observed from midbody to the anterior end. The same variation was observed in our study in B. alfredi and to a lesser degree in B. latastei and $B$. palustre. It is interesting to note that the presence of rows of bristles in both surfaces of the posterior end of females of $B$. variabilis was not observed in other species of Beatogordius from South America and Africa (Schmidt-Rhaesa \& de Villalobos 2002).

\section{DISCUSSION}

Out of the 7 species described in the genus Beatogordius for South America, 5 could be confirmed. $B$. deshayesi has been a misinterpretation and the status of $B$. irregularis appears to be very uncertain, because no generic characters could be found. However, this species could not be investigated and a reinvestigation would certainly clarify its uncertain position. Two new species, $B$. funis and B. palustre could be added to the genus. Sciacchitano (1958) determined two males of $B$. alfredi and two females of $B$. latastei from Africa but the descriptions for the South American specimens of B. alfredi and $B$. latastei differ from the features of the African specimens assigned to these species (Schmidt-Rhaesa \& de Villalobos in press). One of the two African specimens of $B$. alfredi was transferred to B. echinatus and the other to $B$. rhaphaelis and two specimens of $B$. lataste $i$ were assigned to B. echinatus (see Schmidt-Rhaesa \& de Villalobos 2002).

Heinze (1934) created the genus Beatogordius to describe the species of freshwater Nematomorpha with the longitudinal striation of the cuticle caused by longitudinally oriented areoles. In five species from Africa (Schmidt-Rhaesa \& de Villalobos 2002), B. echinatus, B. raphaelis, B. sankurensis, B. ugandensis and B. wilsoni the areoles, be-
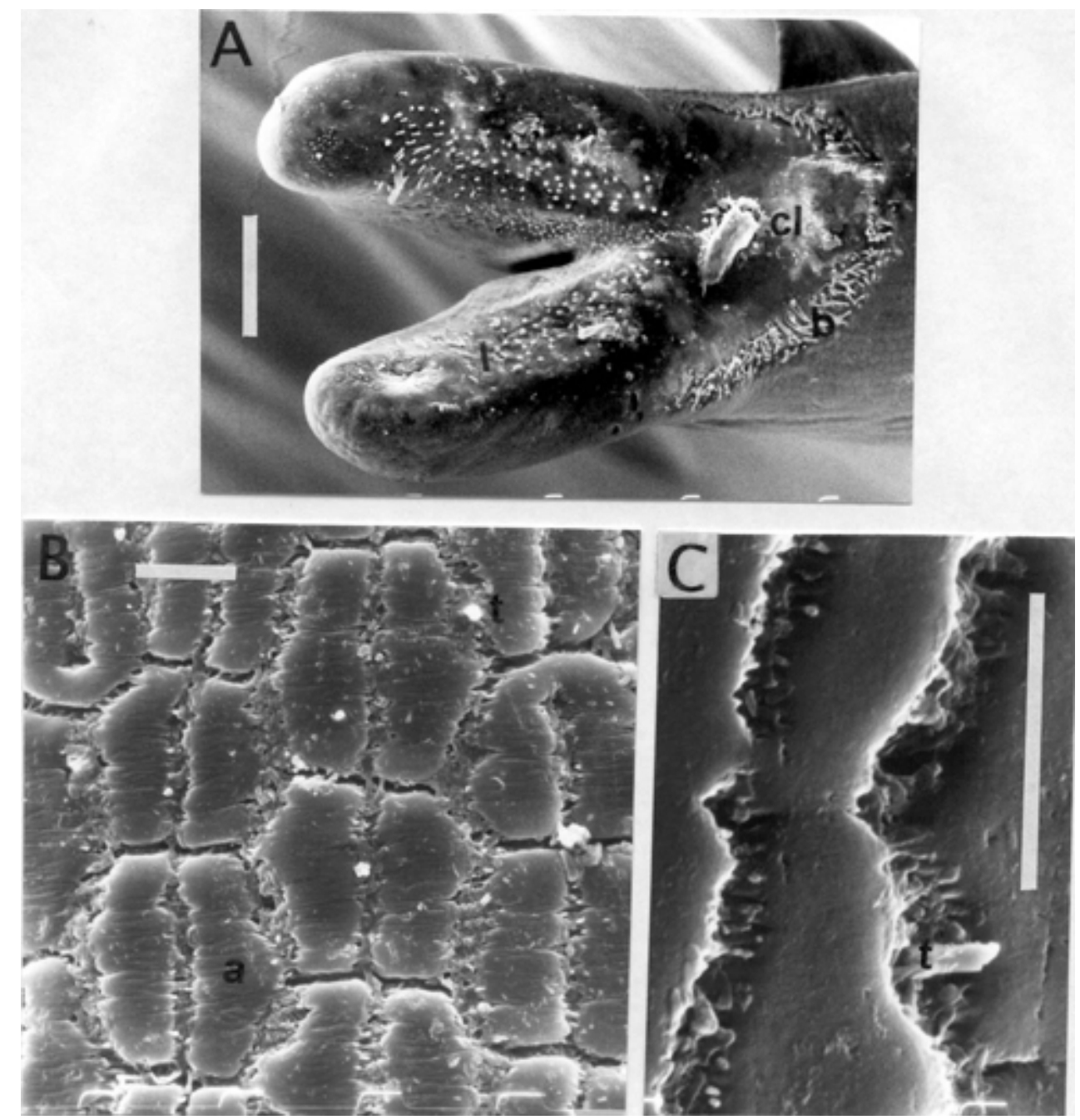

Fig. 7: scanning electron photographs of male of Beatogordius palustre n. sp. A: ventral view of posterior end showing tail lobes, rows of bristles and spines posterior of the cloacal opening, scale bar $=100 \mu \mathrm{m} ; \mathrm{B}, \mathrm{C}$ : cuticle showing areoles with irregular margins, scale bars $=10$ $\mu \mathrm{m}$; a: areoles, b: bristles, cl: cloacal opening, l: lobe, s: post-cloacal spines, t: tubercle 
sides showing the characteristic pattern of the genus, are arranged in the shape of an " $\mathrm{H}$ " where the horizontal element is created by interareolar elements or projections directed anteriorly and posteriorly. Another structure can be present in African species (B. raphaelis, B. abbreviatus and B. ugandensis, B. echinatus) called tubercle areoles. Otherwise, in the South American species neither "horizontal elements" nor tubercle areoles were observed. B. alfredi, B. latastei and B. variabilis from South America showed that the areolar pattern in the anterior end presents a complete modification of the pattern as shown in midbody, the same was observed in B. wilsoni from Africa.
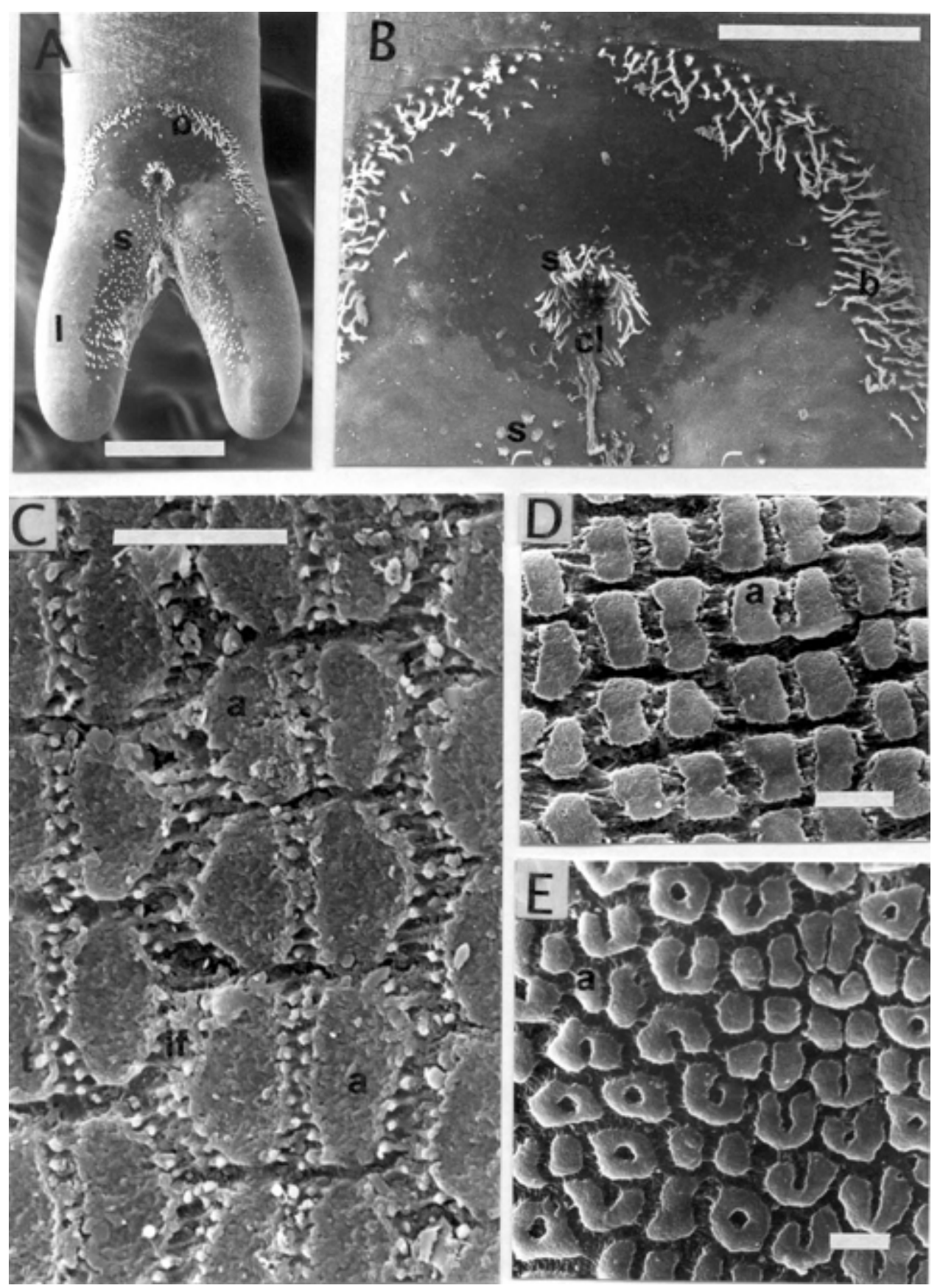

Fig. 8: scanning electron photographs of male of Beatogordius variabilis, holotype. A, B: ventral view of posterior end showing tail lobes, rows of multifurcated bristles, circumcloacal spines and spines posterior of the cloacal opening, scale bars $=\mathrm{A}: 100 \mu \mathrm{m}, \mathrm{B}: 0.20 \mathrm{~mm}$; C: midbody cuticle, scale bar $=10 \mu \mathrm{m} ; \mathrm{D}, \mathrm{E}$ : areolar pattern in the anterior end with complete modification of the pattern as show in midbody, scale bars $=10 \mu \mathrm{m}$; a: areoles, b: bristles, cl: cloacal opening, if: interareolar furrow, l: lobe, s: spines, t: tubercle 
The elongate structures observed in B. abaiconus resemble exactly structures named adhesive warts which have to date only been known from the genus Gordionus (Cham et al. 1983, Schmidt-Rhaesa 2001b) and were regarded even as diagnostic characters for this genus (Müller 1927). The occurrence of adhesive warts in $B$. abaiconus poses some problems. Either, this species is misplaced in the genus Beatogordius which means that pairs of areoles arranged in a longitudinal pattern evolved convergently in Beatogordius and within Gordionus, or adhesive warts are not restricted to Gordionus. In any case this seems to indicate a close relationship between the two genera Beatogordius and Gordionus. The occurrence of rows of bristles in the posterior end of females has to date only been known from females of B. echinatus from Central Africa (Schmidt-Rhaesa \& de Villalobos 2002).
This character is so unique to females which are usually devoid of any such bristles or comparable structures, that the sexes in $B$. echinatus were originally confused (Schmidt-Rhaesa 2001a). The occurrence of such rows in two South American species shows that this character is not restricted to one species. We also demonstrate the close relationship of American and South American species of Beatogordius.

Only a few host species could be observed in the Beatogordius from South America. B. funis was collected emerging from a Blatta orientalis cockroach and $B$. inesae from the vomit of a man. It is interesting to notice that among the species of Beatogordius reported from Africa, four specimens of B. raphaelis were parasitic to Blattodea and one specimen was observed emerging from a child's ureter. Although there are some reports
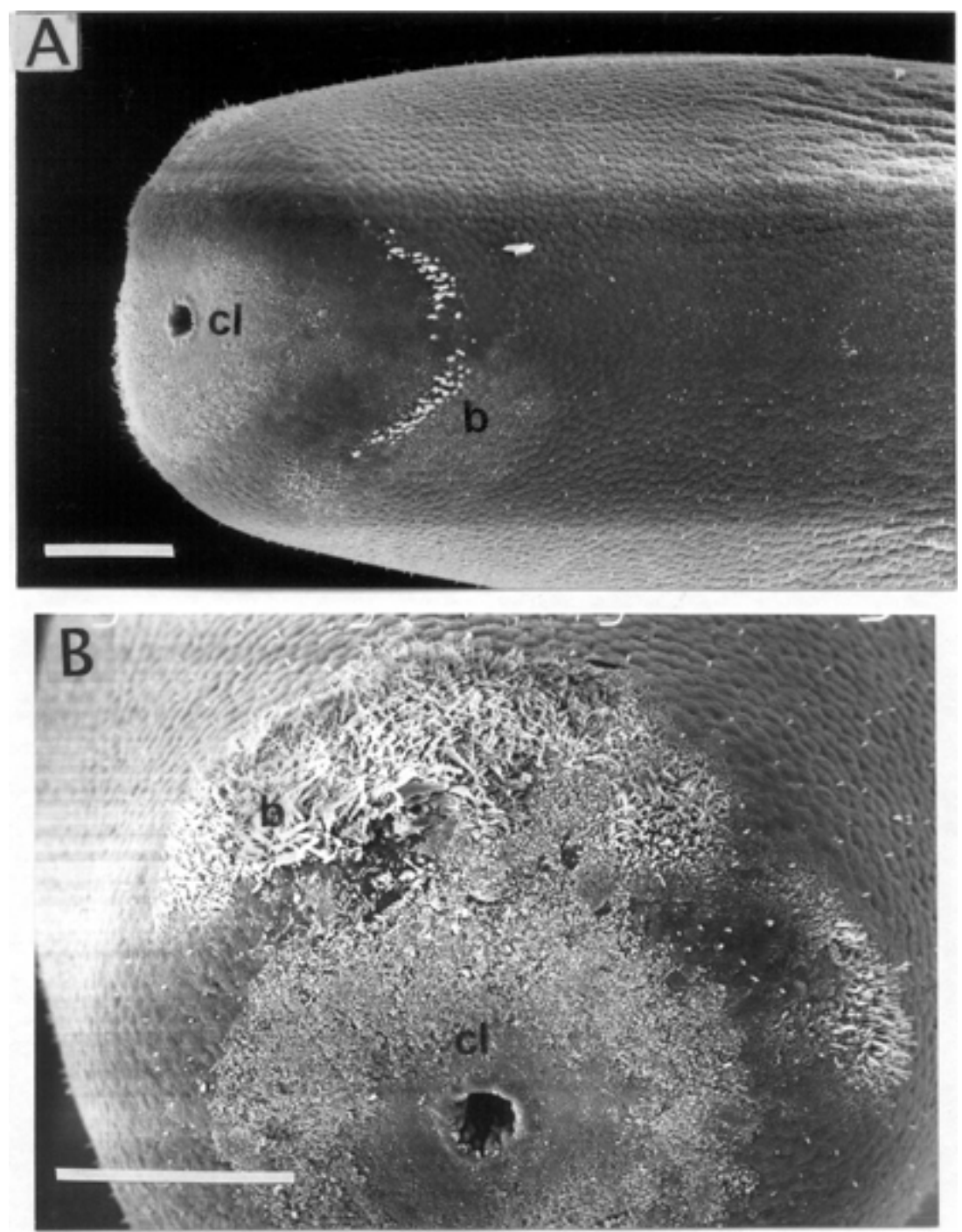

Fig. 9: scanning electron photographs of female posterior end of Beatogordius variabilis, paratype (MLP 3660). A: dorsal view showing a row of bristles, bristles are short and scattered, scale bar $=100 \mu \mathrm{m}$; B: ventral view showing a row of long bristles, scale bar $=100 \mu \mathrm{m} ; \mathrm{b}$ : bristles, cl: cloacal opening 
of human infection (Burger 1972, Cappucci 1982), Herter and Neese (1989) reported one case of pseudoparasitism with Gordius robustus in which crickets were killed and disposed in the toilet, which might have led to the assumption of a human infection with gordiids. From all reported cases it seems unlikely that human may serve as regular hosts or that development is possible (SchmidtRhaesa 2001c).

Most of the South American species have been reported from Argentina, certainly due to the intensive sampling in this area. We think that future studies in other South American areas will provide new records for the genus Beatogordius.

\section{ACKNOWLEDGEMENTS}

To Cristina Damborenea (Museo de Ciencias Naturales, La Plata, Argentina), Jean-Lou Justine (Muséum Nationale d'Historie Naturelle, Paris, France), and Debora Pires (Museu Nacional, Rio de Janeiro, Brazil) for the permission to investigate museum specimens.To Patricia Sarmiento from the Electron Microscopy Service (Museo de Ciencias Naturales, La Plata, Argentina) for preparation of the material.

\section{REFERENCES}

Burger R 1972. Paragordius esavianus passed per urethram. J Urol 108: 469.

Camerano L 1890. Intorno ad una specie di Gordius (G. aeneus Villot) raccolta dal Sig.G.B. Anselmo in Venezuela e intorno alle specie di questo genere fino ad ora descritte dell' America meridionale. Ann Mus Civic Stor Nat Genove 10: 121-127.

Camerano L 1894. Viaggio del dottor Alfredo Borelli nella Repubblica Argentina e nel Paraguay. Boll Mus Zool Anat Comp Torino 9: 1-6.

Camerano L 1895. Description d'une nouvelle especie de Gordius du Chili. Ac Soc Sci Chile 5: 8-9.

Camerano L 1897a. Gordii. Viaggio del Dott. Alfredo Borelli nel Chaco boliviano et Nella Repubblica Argentina. Boll Mus Zool Anat Comp Torino 12: 1-3.

Camerano L 1897b. Monografia dei Gordei. Mem R Accad Sci Torino 47: 339-419.

Camerano L 1915. Revisione dei Gordii. Mem R Acad Sci Torino 66: 1-66.

Cappucci DT 1982. Gordian worms (hairworms): biological and public health aspects. In MG Schultz, Handbook Series in Zoonoses: Parasitic Zoonoses, CRC Press Inc, Boca Raton, Florida, p.193-203.

Carvalho JC 1942. Studies on some Gordiacea of North and South America. J Parasitol 28: 213-222.

Carvalho JC 1944. Considerações sobre alguns gordiáceos brasileiros, com descrição de duas especies novas (Gordiacea, Chordodidae). Rev Bras Biol 4: 485-491.

Carvalho JC 1946. Gordiáceos do Museu de Historia Natural de Montevideo. Com Zool Mus Hist Nat Montevideo 2: 1-7.

Cavalleri F 1961. Descripción de una nueva especie de Gordiaceo Gordius inesae n.sp. (Gordioidea, Gordiidae). Neotropica 7: 1-6.
Cham SA, Seymour MK, Hooper DJ 1983. Observations on a British hairworm, Parachordodes wolterstorffii (Nematomorpha: Gordiidae). J Zool London 199: 275-285.

de Villalobos LC, Ribera I, Bilton DT 2001. First data of Iberian Nematomorpha, with redescription of Gordius aquaticus Linnaeus, G. plicatulus Heinze, Gordionus wolterstorffi (Camerano) and Paragordius tricuspidatus (Dufour). Contributions Zoology 70: 73-84.

Dorier A 1946. Révision de quelques espéces de Gordiacés. Bull Mus Nat Hist Nat 18: 480-494.

Faust EC, Botero Ramos D 1960. Extraordinario hallazgo de una nueva especie de Neochordodes (Gordiacea) en Colombia. In Libro de Homenaje al Dr. Caballero y C. Jubileo 1930-1960, Instituto Politécnico Nacional, México, p. 523527.

Heinze K 1934. Zur Systematik der Gordiiden. Zool Anz 106: 189-192.

Heinze K 1952. Über Gordioidea, eine systematische Studie über Insektenparasiten aus der Grippe der Nematomorpha. Z Parasitenkunde 15: 183-202.

Herter CD, Nesse RE 1989. Pseudoparasitism with Gordius robustus. American Family Physician March 1989: 139142.

Miralles DB 1972. Sobre especies sudamericanas del genero Beatogordius (Nematomorpha, Gordioidea). Neotropica 18: 121-125.

Miralles DB 1981. Nueva especie de Gordiaceo de Sierra de La Ventana. Neotropica 27: 87-90.

Miralles DB 1984. Nueva combinación para gordiaceos argentinos. Beatogordius inesae (Cavalleri) y Beatogordius raphaelis (Camerano). Neotropica 30: 125-126.

Miralles DB 1988. Notas sobre gordiaceos argentinos. IV. Neotropica 34: 62.

Müller GW 1927. Über Gordiaceen. Z Morphol Ökol Tiere 7: 134-219.

Sciacchitano I 1958. Gordioidea del Congo Belga. Ann Mus $R$ Congo Belga 67: 9-111.

Schmidt-Rhaesa A 1997. Nematomorpha. In J Schwoerbel, P Zwick (eds), Sübwasserfauna von Mitteleuropa, Vol. 4/4, Gustav Fischer Verlag, Stuttgart, Germany, p. 1-124.

Schmidt- Rhaesa A 2001a. Reinvestigation and reinterpretation of Chordodiolus echinatus Linstow, 1901, a peculiar nematomorph species. Mitt Mus Nat kd Berl Zool Reihe 77: 91-94.

Schmidt-Rhaesa A 2001b. Variation of cuticular characters in the Nematomorpha: studies on Gordionus violaceus (Baird, 1853) and $G$. Wolterstorffii (Camerano, 1888) from Britain and Ireland. Syst Parasitol 49: 41-57.

Schmidt-Rhaesa A 2001c. The life cycle of horsehair worms (Nematomorpha). Acta Parasitologica 46: 151-158.

Schmidt-Rhaesa A, de Villalobos LC 2002. Revision of the genus Beatogordius (Gordiida, Nematomorpha). I. African species with inclusion of Chordodiolus echinatus (Linstow, 1901). Annls Mus R Afr Centr (Zool) 206 (in press).

Villot A 1874. Monographie des Dragonneaux. Arch Zool Exp Gen 3: 39-72. 